\title{
openheart Revascularisation of patients with end-stage renal disease on chronic haemodialysis: bypass surgery versus PCI - analysis of routine statutory health insurance data
}

\author{
Martin Möckel, ${ }^{1}$ Julia Searle, ${ }^{1}$ Henning Thomas Baberg, ${ }^{2}$ Peter Dirschedl, ${ }^{3}$ \\ Benny Levenson, ${ }^{4}$ Jürgen Malzahn, ${ }^{5}$ Thomas Mansky, ${ }^{6}$ Christian Günster, ${ }^{7}$ \\ Elke Jeschke ${ }^{7}$
}

To cite: Möckel M, Searle J, Baberg HT, et al.

Revascularisation of patients with end-stage renal disease on chronic haemodialysis: bypass surgery versus $\mathrm{PCl}$ analysis of routine statutory health insurance data. Open Heart 2016;3:e000464. doi:10.1136/openhrt-2016000464

Received 10 May 2016 Revised 28 July 2016 Accepted 8 August 2016

CrossMark

For numbered affiliations see end of article.

Correspondence to Professor Martin Möckel; martin.moeckel@charite.de

\section{ABSTRACT}

Objectives: We aimed to analyse the short-term and long-term outcome of patients with end-stage renal disease (ESRD) undergoing percutaneous intervention (PCI) as compared to coronary artery bypass surgery (CABG) to evaluate the optimal coronary revascularisation strategy.

Design: Retrospective analysis of routine statutory health insurance data between 2010 and 2012.

Main outcome measures: Primary outcome was adjusted all-cause mortality after 30 days and major adverse cardiovascular and cerebrovascular events at 1 year. Secondary outcomes were repeat revascularisation at 30 days and 1 year and bleeding events within 7 days.

Results: The total number of cases was $n=4123$ (PCl; $\mathrm{n}=3417$ ), median age was 71 (IQR 62-77), 30.4\% were women. The adjusted $\mathrm{OR}$ for death within 30 days was 0.59 (95\% Cl 0.43 to 0.81$)$ for patients undergoing $\mathrm{PCl}$ versus $\mathrm{CABG}$. At 1 year, the adjusted $\mathrm{OR}$ for major adverse cardiac and cerebrovascular events (MACCE) was 1.58 (1.32 to 1.89) for PCI versus CABG and 1.47 (1.23 to 1.75) for all-cause death. In the subgroup of patients with acute myocardial infarction (AMI), adjusted all-cause mortality at 30 days did not differ significantly between both groups (OR 0.75 (0.47 to 1.20)), whereas in patients without $A M I$ the OR for 30-day mortality was 0.44 (0.28 to 0.68) for PCI versus CABG. At 1 year, the adjusted OR for MACCE in patients with AMI was 1.40 (1.06 to 1.85) for PCI versus CABG and 1.47 (1.08 to 1.99) for mortality.

Conclusions: In this cohort of unselected patients with ESRD undergoing revascularisation, the 1-year outcome was better for CABG in patients with and without AMI. The 30-day mortality was higher in non-AMI patients with CABG reflecting an early hazard with surgery. In cases where the patient's characteristics and risk profile make it difficult to decide on a revascularisation strategy, $\mathrm{CABG}$ could be the preferred option.

\section{KEY QUESTIONS}

What is already known about this subject?

- Current evidence on the optimal coronary revascularisation strategy in patients with end-stage renal disease (ESRD) is largely derived from large, US-based registries. There are no randomised controlled trials on this topic. A total of five systematic review articles with meta-analyses have been published. They too, are mainly based on the registry data from the USA and a few small observational studies are mainly from Asia. Only one very small study from a European country is included in any of these review articles and no European study has been published in the past 10 years. Additionally, there is a lack of data on revascularisation in patients with ESRD with acute myocardial infarction (AMI), as these patients were either excluded or not analysed separately. So far, the majority of studies report a reduced risk for short-term mortality for patients with ESRD treated with percutaneous intervention $(\mathrm{PCI})$ but a reduced risk for long-term mortality when treated with coronary artery bypass grafting (CABG).

What does this study add?

- This study is the first to report large-scale data from a European country. Additionally, this is one of the two studies (and again the only European study) reporting data for patients with ESRD with AMI.

How might this impact clinical practice?

- Despite the lack of prospective randomised trials, there is good evidence that CABG should be the preferred revascularisation strategy in patients with ESRD with stable coronary artery disease. In patients with AMI, patients might benefit from an early revascularisation of an occluded culprit vessel with PCI. Elective CABG surgery could be considered, to reduce the longterm mortality in this patient group. 


\section{INTRODUCTION}

Patients with end-stage renal disease (ESRD) requiring haemodialysis have a high risk of coronary artery disease $(\mathrm{CAD})$. Coronary revascularisation of this vulnerable patient group is challenging due to the high cardiovascular morbidity and mortality even after therapy. ${ }^{1}$ The current 2014 European Society of Cardiology (ESC) / European Association for Cardio-Thoracic Surgery (EACTS) Guidelines on myocardial revascularisation ${ }^{2}$ recommend the use of coronary artery bypass grafting (CABG) over percutaneous intervention (PCI) in patients with moderate or severe kidney disease and multivessel CAD on the basis of a large US registry. ${ }^{3}$ Nevertheless, the outcome in this cohort was poor with unadjusted 5-year survival rates of only $22-25 \%$ for both strategies. ${ }^{3}$ Recent data from patients on the transplant waiting list highlight the need for additional research specifically for patients on haemodialysis, as PCI did not show a large benefit over conservative strategies in this small observational study. ${ }^{4}$ Systematic reviews of studies comparing CABG and PCI in patients with ESRD showed that CABG was mostly associated with a lower relative risk of long-term mortality, acute myocardial infarction (AMI) and repeat revascularisation, but with a higher relative risk of short-term mortality when compared to PCI. ${ }^{5-9}$

All systematic reviews are largely based on the same studies, which predominantly present data from the USA and Canada and from a few very small studies from Asia. Additionally, a large part of the studies included in the reviews date back into the 1990s. Of the studies performed since 2000, none originated from a European country.

In the absence of European studies and the absence of prospective randomised trials we analysed a large set of unselected statutory health insurance data to compare the 30 days and 1-year mortality and proportion of major adverse cardiac and cerebrovascular events (MACCE) in patients with ESRD who underwent either coronary revascularisation by $\mathrm{PCI}$ or by CABG in Germany. The analysis includes patients under current state-of-the-art interventional drug-eluting stents (DESs) and surgical standards. In a subgroup analyses, we aimed to assess differences in outcomes between patients with and without myocardial infarction (MI).

\section{METHODS}

This is a retrospective analysis of anonymised data of the German healthcare insurance 'Allgemeine Ortskrankenkasse' (AOK). AOK is the largest provider of nationwide statutory healthcare insurance in Germany ( $\sim 30 \%$ of the German population). Every person is allowed to enrol in the AOK regardless of age, comorbidity, income or type of employment. ${ }^{10}$ The data were derived from the billing data for inpatient and outpatient treatment. They comprise a unique identification number, age, sex, main diagnosis and comorbidities, procedures, length of hospital stays, patient survival and insurance status. Diagnoses were coded according to the 10th revision of the International Classification of Diseases (ICD-10). ${ }^{11}$ Procedures were documented using the German version of the International Classification of Procedures in Medicine (ICPM), the 'Operationen- und Prozeduren Schlüssel' (OPS) for inpatients and the Doctors' Fee Scale within the Statutory Health Insurance Scheme 'Einheitlicher Bewertungsmaßstab' (EBM) for outpatients. ${ }^{12}$

The present study is based on anonymised data provided by hospitals and outpatient physicians for health insurance accounting. The recommendations for good practice in secondary data analysis developed by the German Working Group on the Collection and Use of Secondary Data were applied in full. Therefore no formal ethical committee approval was needed.

\section{Study population}

All in-hospital patients with ESRD were included in the study who underwent coronary revascularisation between January 2010 and December 2012 (admission date). The hospitalisation associated with the initial revascularisation procedure is referred to as 'index hospitalisation'. Patients with ESRD were defined as having had inpatient or outpatient dialysis at least once in the year prior to admission. Dialyses were identified as OPS codes ' $8-853$.X to $8-858 . \mathrm{X}$ ' for inpatients and as EBM codes ' 40800 to 40808 ' for outpatients. Coronary revascularisation was defined either by CABG or PCI, defined as OPS codes '5-361.X, 5-362.X' for CABG and '8-837.X' for PCI. We excluded patients receiving both CABG and PCI during the index hospitalisation. Patients with renal transplantation were defined as OPS codes '5-555.X', any type of cardiac surgery were defined as OPS codes '5-35X, 5-36X' and PCI in the year preceding admission were also excluded.

\section{Patient involvement}

Owing to the applied method, that is, ex post analysis of anonymous administrative data, patients and caregivers were not involved in either recruitment or conduct of this study, nor were they involved in the development of the design and outcome measurements of this study.

\section{Outcomes}

The primary outcome was all-cause mortality at 30 days and 1 year from the date of admission.

AOK gets notified of a member's death, and the membership is cancelled. The insurance companies receive information on the date of death, but not on the cause of death. Secondary outcomes were MACCE, repeat revascularisation procedures (CABG or PCI) and coronary angiography within 1 year. MACCE was defined as death, AMI, stroke or transient ischaemic attack (TIA). AMI was defined as ICD-10 diagnosis I21, including ST-elevation myocardial infarction (STEMI) and non-STEMI (NSTEMI). Stroke was defined as diagnoses 
I63 and TIA as diagnoses G45. An AMI occurring during the index hospitalisation was not considered an outcome, since it may have occurred prior to the revascularisation.

\section{Statistics}

Descriptive statistics such as medians and IQRs and proportions were used to describe differences in baseline characteristics. The two-tailed $\chi^{2}$ test and the Kruskal-Wallis test were used to analyse group differences. Subgroup analyses were performed for patients with AMI at index hospitalisation. ORs were calculated for each outcome. To assess the association between the strategy for revascularisation and outcomes, multivariable logistic regression models were conducted using stepwise backward selection based on the likelihood ratio statistics. Adjusted OR and 95\% CIs were calculated. Adjustment was made for sex, age and comorbidities according to Elixhauser definition, ${ }^{13}$ AMI, cardiogenic shock, the New York Heart Association (NYHA) class (I vs II, III or IV), left main disease, multivessel disease (two or three vessels) at index hospitalisation and AMI in the year preceding admission. The Elixhauser measure was developed in 1998 to predict mortality from administrative data. The definition includes 31 acute and chronic comorbidities: congestive heart failure, cardiac arrhythmias, valvular disease, pulmonary circulation disorders, peripheral vascular disease, hypertension uncomplicated, hypertension complicated, diabetes uncomplicated, diabetes complicated (ie, coma, ketoacidosis, vascular disease), renal failure, liver disease, coagulopathy, blood loss anaemia, deficiency anaemia, hypothyroidism, peptic ulcer disease excluding bleeding, chronic obstructive pulmonary disease (COPD), obesity (body mass index $\geq 30 \mathrm{~kg} / \mathrm{m}^{2}$ ), weight loss, solid tumour without metastasis, metastatic cancer, lymphoma, fluid and electrolyte disorders, rheumatoid arthritis/collagen vascular diseases, paralysis, other neurological disorders, alcohol abuse, drug abuse, psychoses, depression and AIDS/HIV. Comorbidities were identified using the coding algorithm by Quan et $a l^{14}$ based on the ICD-10 coding. AMI, cardiogenic shock, NYHA class (I vs II, III or IV), left main disease and multivessel disease (two or three vessels), which are not included in the Elixhauser measure, were also analysed because they are potential risk factors and differ between the PCI and the CABG groups $(\mathrm{p}<0.005)$.

Age was entered as a continuous variable. Other variables were entered as separate dichotomous variables. Data were censored in the analyses in case of death and AOK membership termination $(2.74 \% / \mathrm{n}=113)$. Hospitals are legally bound ( $\$ 301$ SGB V) to transmit complete data sets to the health insurance companies for all inpatients. For this reason, there are no missing data. All analyses were performed using STATA V.11.2 (StataCorp, College Station, Texas, USA).

\section{RESULTS}

We included $n=4123$ cases corresponding to $n=3961$ patients. All double interventions except one were PCIs. Compared to CABG, the frequency of PCI was higher with $82.88 \%$ over the 3 years period (2010: $81.17 \%$; 2011: 83.13\%; 2012: 84.20\%). Figure 1 shows the included cases with respect to the reperfusion strategy and the diagnosis of AMI.

Table 1 shows the characteristics of the patients. The patients in the CABG group were slightly younger (69 vs 72 years) and there were less women.

Table 2 shows event proportions for the defined outcomes. The 30 days mortality was significantly higher in the CABG group $(p=0.002)$. After 1 year, the mortality was nearly identical but the MACCE rate was higher for

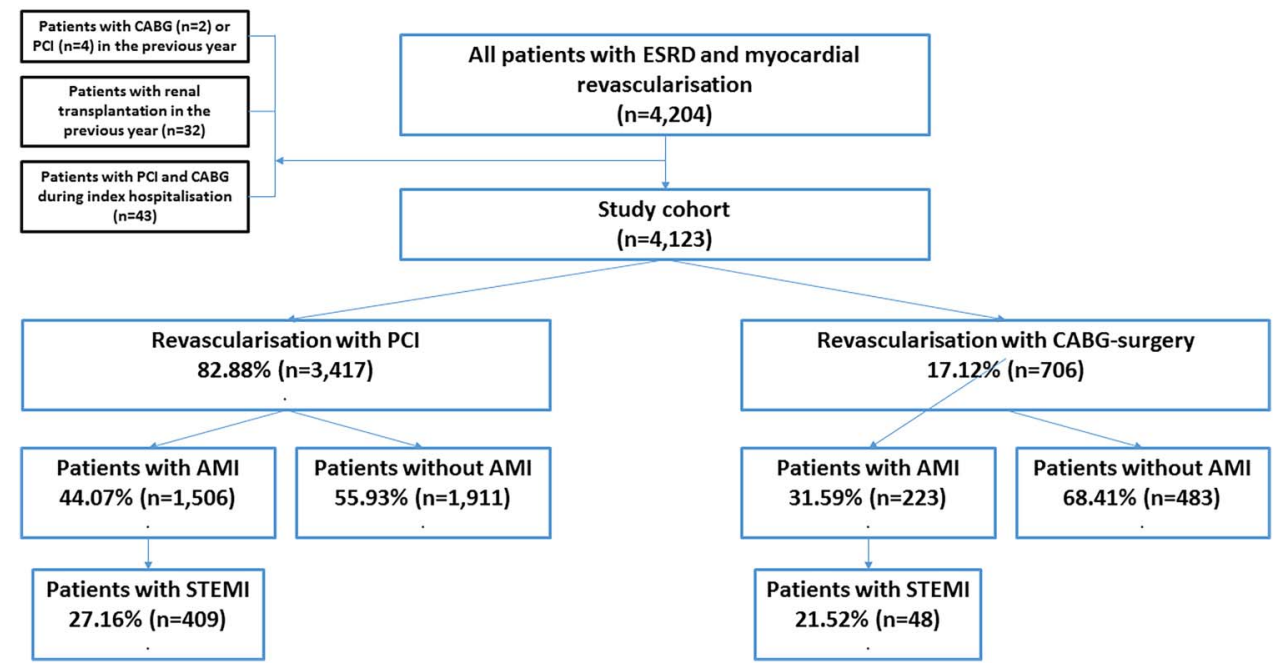

Figure 1 Flow chart indicating the cohort of patients included in the analysis. Patients were included if their index hospitalisation occurred during the predefined study period (January 2010-December 2012). The inclusion and exclusion criteria are outlined in the methods section. 
PCI driven by significantly more MI $(\mathrm{p}<0.001)$. The bleeding rate was similar in both groups.

Table 3 shows the OR for both revascularisation strategies. Mortality within 30 days was significantly lower in the PCI group with an adjusted OR of 0.59 (0.43 to 0.81) compared to CABG. One-year outcome is better in the CABG group, with an adjusted OR for MACCE within 1 year of 1.58 (1.32 to 1.89 ). The frequency for both, CABG and PCI treatments within 1 year after the index revascularisation, is significantly higher in the PCI group. The same is true for bleeding events within 7 days after the index intervention.

Tables 4 and 5 show the subanalysis of patients with and without AMI. For patients with AMI (table 4) there was no difference in 30 days mortality between PCI and $\mathrm{CABG}$, but there was a non-significant trend towards more patients with STEMI in the PCI group $(27.16 \%$ vs.
$21.52 \%, \mathrm{p}=0.06)$. Patients with STEMI had a higher risk of death within 30 days ( $\mathrm{OR}=2.16$ (1.56 to 2.98) and therefore a potential negative influence on survival in the PCI group and is therefore included in the variables for adjustment. After 1 year, the CABG group had better survival and less repeat interventions compared to the PCI group. This is independent of the diagnosis of STEMI in the index hospital stay.

In patients without AMI, the 30 days mortality was significantly lower with PCI, but after 1 year survival was better with CABG and repeat interventions and MI occurred less often in the CABG group (table 5).

\section{DISCUSSION}

Our study is the first to analyse a large European routine data set, using health insurance data from 4123

Table 1 Patient characteristics, for all patients and for the subgroups of patients with $\mathrm{PCl}$ and $\mathrm{CABG}$

\begin{tabular}{|c|c|c|c|c|}
\hline Variable & $\begin{array}{l}\text { Total (n (\%)) } \\
4123(100 \%)\end{array}$ & $\begin{array}{l}\mathrm{PCI}(\mathrm{n}(\%)) \\
3417(100 \%)\end{array}$ & $\begin{array}{l}\text { CABG (n (\%)) } \\
706(100 \%)\end{array}$ & p Value \\
\hline Age in years (median (IQR)) & $71(62-77)$ & $72(63-77)$ & $69(60-74)$ & $<0.001$ \\
\hline Female patients & $1252(30.37 \%)$ & $1087(31.81 \%)$ & $165(23.37 \%)$ & $<0.001$ \\
\hline \multicolumn{5}{|l|}{ Diagnoses at the index hospital stay* } \\
\hline \multicolumn{5}{|l|}{ Cardiovascular diseases } \\
\hline AMI & $1729(41.94 \%)$ & $1506(44.07 \%)$ & $223(31.59 \%)$ & $<0.001$ \\
\hline Prior Ml & 499 (12.10\%) & $383(11.21 \%)$ & $116(16.43 \%)$ & $<0.001$ \\
\hline Stroke & $78(1.89 \%)$ & $47(1.38 \%)$ & $31(4.39 \%)$ & $<0.001$ \\
\hline TIA & $14(0.34 \%)$ & $12(0.35 \%)$ & $2(0.28 \%)$ & 0.778 \\
\hline Intracerebral bleeding & $6(0.15 \%)$ & $4(0.12 \%)$ & $2(0.28 \%)$ & 0.292 \\
\hline Congestive heart failure & $2059(47.10 \%)$ & $1649(48.26 \%)$ & $410(58.07 \%)$ & $<0.001$ \\
\hline NYHA-stage $>1$ & $1685(40.87 \%)$ & $1323(38.72 \%)$ & $362(51.27 \%)$ & $<0.001$ \\
\hline Coronary 2-vessel disease & $1020(24.74 \%)$ & 884 (25.87\%) & $136(19.26 \%)$ & $<0.001$ \\
\hline Coronary 3-vessel disease & $2236(54.23 \%)$ & $1678(49.11 \%)$ & $558(79.04 \%)$ & $<0.001$ \\
\hline Left main disease & $435(10.55 \%)$ & $220(6.44 \%)$ & $215(30.45 \%)$ & $<0.001$ \\
\hline Shock & $248(6.02 \%)$ & $189(5.53 \%)$ & $59(8.36 \%)$ & 0.004 \\
\hline Hypertension & $3211(77.88 \%)$ & $2595(75.94 \%)$ & $616(87.25 \%)$ & $<0.001$ \\
\hline Cardiac arrhythmia & $1814(44.00 \%)$ & $1408(41.21 \%)$ & $406(57.51 \%)$ & $<0.001$ \\
\hline Valvular disease & $1026(24.88 \%)$ & $727(21.28 \%)$ & $299(42.35 \%)$ & $<0.001$ \\
\hline Peripheral vascular disorders & $1455(35.29 \%)$ & $1121(32.81 \%)$ & $334(47.31 \%)$ & $<0.001$ \\
\hline \multicolumn{5}{|l|}{ Other concomitant diseases } \\
\hline Diabetes mellitus & $2263(54.89 \%)$ & $1864(54.55 \%)$ & $399(56.52 \%)$ & 0.340 \\
\hline Chronic obstructive pulmonary disease & $549(13.32 \%)$ & $420(12.29 \%)$ & $129(18.27 \%)$ & $<0.001$ \\
\hline Coagulopathy & $486(11.79 \%)$ & $224(6.56 \%)$ & $262(37.11 \%)$ & $<0.001$ \\
\hline Hypothyroidism & 449 (10.89\%) & $366(10.71 \%)$ & $83(11.76 \%)$ & 0.417 \\
\hline Obesity $\left(\mathrm{BMI} \geq 30 \mathrm{~kg} / \mathrm{m}^{2}\right)$ & 442 (10.72\%) & $310(9.07 \%)$ & $132(18.70 \%)$ & $<0.001$ \\
\hline \multicolumn{5}{|l|}{ Interventions at index hospital stay (\%) } \\
\hline BMS & $1460(35.41 \%)$ & $1460(42.73 \%)$ & - & - \\
\hline DES & $1519(36.84 \%)$ & $1519(44.45 \%)$ & - & - \\
\hline $\mathrm{PCl}>1$ coronary artery $\dagger$ & $464(11.25 \%)$ & $464(13.58 \%)$ & - & - \\
\hline Pacemaker implantation & $90(2.18 \%)$ & $67(1.96 \%)$ & $23(3.26 \%)$ & 0.032 \\
\hline ICD implantation & $35(0.85 \%)$ & $34(1.00 \%)$ & $1(0.14 \%)$ & 0.024 \\
\hline
\end{tabular}

The $\mathrm{p}$ value was calculated using Kruskal-Wallis test for age and two-tailed $\chi^{2}$ test all other variables.

*Other analysed comorbidities according to Elixhauser et al with frequency $<5 \%$ are not shown (pulmonary circulation disorders, liver disease, blood loss anaemia, deficiency anaemia, peptic ulcer disease excluding bleeding, weight loss, solid tumour without metastasis, metastatic cancer, lymphoma, fluid and electrolyte disorders, rheumatoid arthritis/collagen vascular diseases, paralysis, other neurological disorders, alcohol abuse, drug abuse, psychoses, depression and AIDS/HIV).

†At least two stents in one or more coronary arteries during the index hospitalisation.

AMI, acute myocardial infarction; BMS, bare metal stent; CABG, coronary artery bypass graft; DES, drug-eluting stent; ICD, implantable cardioverter defibrillator; NYHA, New York Heart Association; PCI, percutaneous coronary intervention; TIA, transient ischaemic attack. 
Table 2 Event proportions for patients undergoing $\mathrm{PCI}$ or $\mathrm{CABG}$

\begin{tabular}{|c|c|c|}
\hline Outcome & $\begin{array}{l}\mathrm{PCl}(\mathrm{n}(\%)) \\
3417(100 \%)\end{array}$ & $\begin{array}{l}\text { CABG (n (\%)) } \\
706(100 \%)\end{array}$ \\
\hline Mortality within 30 days & $318(9.31)$ & $93(13.17)$ \\
\hline MACCE within 1 year & $1287(38.68)$ & $249(36.46)$ \\
\hline Mortality & $1044(31.41)$ & $216(31.49)$ \\
\hline Myocardial infarction & $281(11.81)$ & $24(5.11)$ \\
\hline Stroke & $63(2.75)$ & $10(2.12)$ \\
\hline TIA & $28(1.23)$ & $3(0.64)$ \\
\hline CABG up to 1 year after index hospital stay & $60(2.62)$ & $1(0.21)$ \\
\hline Within 30 days & $8(0.28)$ & $0(0.00)$ \\
\hline 31 days until 365 days & $52(2.27)$ & $1(0.21)$ \\
\hline $\mathrm{PCl}$ up to 1 year after index hospital stay & 739 (26.39) & $31(6.60)$ \\
\hline Within 90 days & $341(12.27)$ & $9(1.71)$ \\
\hline 91 days until 365 days & $298(12.31)$ & $22(4.86)$ \\
\hline Coronary angiography up to 1 year after index hospital stay & 969 (38.93) & $52(10.95)$ \\
\hline Bleeding during hospital stay or transfusion within 7 days after the intervention/operation & $524(15.34)$ & $94(13.31)$ \\
\hline
\end{tabular}

Table 3 ORs for the interventional treatment $(\mathrm{PCI})$ (reference: $\mathrm{CABG}$ )

\begin{tabular}{|c|c|c|}
\hline Outcome & $\begin{array}{l}\text { Adjusted OR } \\
(95 \% \mathrm{Cl})^{*}\end{array}$ & $\begin{array}{l}\text { Crude OR } \\
(95 \% \mathrm{Cl})\end{array}$ \\
\hline Mortality within 30 days & $0.59(0.43$ to 0.81$)$ & $0.68(0.52$ to 0.89$)$ \\
\hline MACCE within 1 year & 1.58 (1.32 to 1.89$)$ & $1.09(0.92$ to 1.31$)$ \\
\hline Mortality & $1.47(1.23$ to 1.75$)$ & $1.00(0.84$ to 1.18$)$ \\
\hline Myocardial infarction & $2.30(1.49$ to 3.53$)$ & $2.49(1.67$ to 3.71$)$ \\
\hline Stroke & $1.46(0.78$ to 2.72$)$ & 1.30 (0.73 to 2.33$)$ \\
\hline TIA & $3.55(1.06$ to 11.89$)$ & $1.94(0.59$ to 6.31$)$ \\
\hline $\mathrm{PCl}$ up to 1 year after index hospital stay & 5.69 (3.81 to 8.50$)$ & 5.08 (3.46 to 7.44$)$ \\
\hline Within 90 days & $8.94(4.49$ to 17.81$)$ & $8.02(4.05$ to 15.87$)$ \\
\hline 91 days until 365 days & $3.84(2.42$ to 6.01$)$ & $2.86(1.80$ to 4.54$)$ \\
\hline Coronary angiography up to 1 year after index hospital stay & 6.14 (4.39 to 8.58$)$ & 5.19 (3.73 to 7.20$)$ \\
\hline $\begin{array}{l}\text { Bleeding during hospital stay or transfusion within } \\
7 \text { days after the intervention/operation }\end{array}$ & 1.58 (1.09 to 2.29$)$ & $1.18(0.93$ to 1.49$)$ \\
\hline \multicolumn{3}{|c|}{$\begin{array}{l}{ }^{*} \text { Risk adjustment: age, sex, comorbidities according to Elixhauser, myocardial infarction/STEMI, Shock, NYHA-stadium >1, 2-rsp. 3-coronary } \\
\text { vessel disease, left main disease during index hospital stay or myocardial infarction in the year before. CABG surgery during the one-year } \\
\text { follow-up period after the index event only occurred once in the CABG group and did not occur in the PCI group. } \\
\text { CABG, coronary artery bypass graft; MACCE, major cardiovascular or cerebrovascular event; PCI, percutaneous coronary intervention; TIA, } \\
\text { transient ischaemic attack. }\end{array}$} \\
\hline
\end{tabular}

patients with ESRD on dialysis who underwent myocardial revascularisation during a 3-year period. Importantly, our study is one of the two studies published in the past 10 years which included and specifically reported results for patients with AMI during the index hospitalisation.

Our analysis shows that, even though patients with ESRD with PCI had a lower short-term mortality, 1-year results regarding mortality, AMI and combined MACCE as well as bleeding events and repeat revascularisation were significantly less frequent in patients undergoing bypass surgery. In the subgroup of patients who were admitted with AMI, the 30-day outcome did not significantly differ between the PCI and CABG groups whereas, again, the 1-year outcome was better in the
CABG group regarding all outcomes, except for recurrent AMI. Given the lack of European data and of prospective randomised trials and the resulting lack of clear evidence-based guideline recommendations on the optimal therapeutic strategy, our large-scale and unselected data provide important support that surgical therapy should be favoured, where possible.

\section{Current evidence}

Our analysis largely confirms the results of systematic reviews and meta-analyses on this topic. Zheng et a ${ }^{9}$ evaluated 16 retrospective, observational trials (1990 until 2010) with a total number of 32350 patients with ESRD with $\mathrm{CAD}$ and a minimal follow-up time of 12 months, where patients with CABG had a lower long-term 
Table 4 ORs for the interventional treatment $(\mathrm{PCI})$ of patients with acute myocardial infarction (reference: $\mathrm{CABG}$ )

\begin{tabular}{|c|c|c|}
\hline & $\begin{array}{l}\text { Adjusted OR }(95 \% \mathrm{CI})^{\star} \text { for } \\
\text { patients with AMI }\end{array}$ & $\begin{array}{l}\text { Crude OR }(95 \% \mathrm{Cl}) \text { for } \\
\text { patients with AMI }\end{array}$ \\
\hline Mortality within 30 days & $0.75(0.47$ to 1.20$)$ & $0.74(0.42$ to 1.30$)$ \\
\hline MACCE within 1 year & $1.40(1.06$ to 1.85$)$ & $1.04(0.80$ to 1.34$)$ \\
\hline Mortality & $1.47(1.08$ to 1.99$)$ & $1.02(0.77$ to 1.36$)$ \\
\hline Myocardial infarction & 1.67 (0.99 to 2.80$)$ & 1.76 (1.08 to 2.86$)$ \\
\hline Stroke & $1.16(0.36$ to 3.80$)$ & $1.47(0.47$ to 4.61$)$ \\
\hline TIA & $4.05(0.42$ to 39.11$)$ & $1.93(0.25$ to 14.74$)$ \\
\hline $\mathrm{PCl}$ up to 1 year after index hospital stay & 5.43 (2.96 to 9.96$)$ & 4.30 (2.36 to 7.85$)$ \\
\hline Within 90 days & 4.39 (2.02 to 9.54$)$ & 4.08 (1.89 to 8.81$)$ \\
\hline 91 days until 365 days & 4.36 (1.95 to 9.72$)$ & $3.30(1.44$ to 7.55$)$ \\
\hline $\begin{array}{l}\text { Coronary angiography up to } 1 \text { year after index } \\
\text { hospital stay }\end{array}$ & 5.38 (3.20 to 9.06$)$ & 4.54 (2.73 to 7.53$)$ \\
\hline $\begin{array}{l}\text { Bleeding during hospital stay or transfusion within } \\
7 \text { days after the intervention/operation }\end{array}$ & 1.96 (1.18 to 3.24$)$ & $1.43(0.89$ to 2.31$)$ \\
\hline
\end{tabular}

Table 5 ORs for the interventional treatment (PCI) of patients without acute myocardial infarction (reference: $\mathrm{CABG}$ )

\begin{tabular}{|c|c|c|}
\hline & $\begin{array}{l}\text { Adjusted OR }(95 \% \mathrm{Cl})^{\star} \text { for } \\
\text { patients without } \mathrm{AMI}\end{array}$ & $\begin{array}{l}\text { Crude OR }(95 \% \mathrm{Cl}) \text { for patients } \\
\text { without AMI }\end{array}$ \\
\hline Mortality within 30 days & $0.44(0.28$ to 0.68$)$ & $0.35(0.24$ to 0.51$)$ \\
\hline MACCE within 1 year & $1.82(1.44$ to 2.31$)$ & 1.90 (1.47 to 2.45$)$ \\
\hline Mortality & 1.45 (1.16 to 1.83$)$ & 1.67 (1.29 to 2.16$)$ \\
\hline Myocardial infarction & 3.44 (1.63 to 7.25$)$ & 2.89 (1.39 to 6.03$)$ \\
\hline Stroke & $0.95(0.46$ to 1.97$)$ & $1.82(0.45$ to 7.39$)$ \\
\hline TIA & $2.66(0.72$ to 9.76$)$ & $6.37(0.90$ to 45.10$)$ \\
\hline $\mathrm{PCl}$ up to 1 year after index hospital stay & 7.09 (4.30 to 11.69$)$ & 5.23 (3.19 to 8.57$)$ \\
\hline Within 30 days & 17.29 (5.35 to 55.90$)$ & 15.03 (4.99 to 45.29$)$ \\
\hline 31 days until 365 days & 2.73 (1.52 to 4.88$)$ & 2.58 (1.46 to 4.55$)$ \\
\hline $\begin{array}{l}\text { Coronary angiography up to } 1 \text { year after index } \\
\text { hospital stay }\end{array}$ & 6.03 (3.99 to 9.13$)$ & 5.28 (3.52 to 7.90$)$ \\
\hline $\begin{array}{l}\text { Bleeding during hospital stay or transfusion within } \\
7 \text { days after the intervention/operation }\end{array}$ & 1.36 (0.83 to 2.22$)$ & $0.89(0.61$ to 1.32$)$ \\
\hline
\end{tabular}

mortality and ORs for MI and repeat revascularisation, while short-term mortality was lower in the PCI group. All studies included in this meta-analysis originated from the USA, Canada, Germany $(n=1,40$ patients included $)^{15}$ and Japan, including two 2 large-scale US studies, which provided the majority of the analysed patients $\left(n=30090\right.$ of $n=32350$ in total). ${ }^{1617}$

Both US studies used data from the USA Renal Data System (USRDS) database, a national registry of the ESRD Medicare population in the USA, looking at patients on dialysis who were hospitalised from 1978 to $1995^{16}$ and 1995 to $1998 .^{17}$

Other systematic reviews published in recent years basically evaluate the same studies with a high proportion of studies dating far back. ${ }^{5-9}$ The only exception is a review by Deo et $a l^{8}{ }^{8}$ who only included studies published since the year 2000. The review by Kannan et $a \bar{l}$ additionally includes a large study which analysed USRDS data from 1997 to 2009. ${ }^{3}$ Interestingly, the proportion of CABG in all studies included in the study Zheng et al was $47 \%$, as compared to $17 \%$ in our cohort, reflecting that most data were generated in the early 1990s when PCI was not as predominantly used as it is today. Data on the temporal development of revascularisation strategy use show consistently higher numbers of PCI as compared to CABG in recent years. ${ }^{18} 19$

Recently, Bangalore et al published a registry study with data from the New York State Coronary Reporting 
System and Cardiac Surgery Reporting system on 11305 patients with chronic kidney disease (CKD) and multivessel coronary disease. This included a prespecified analysis of patients on dialysis with matched CABG/PCI pairs based on a propensity score ( $\mathrm{n}=243$ per group). Again, PCI was associated with a higher long-term risk (HR 2.02 (1.4 to 2.93)) as compared to CABG, with also a higher risk of repeat revascularisation and AMI. ${ }^{20}$ Krishnaswami et al published data from Kaiser Permanente Northern California (KPNC), which is reported as a healthcare delivery system with 33 million members. Of the 1015 patients on chronic dialysis who underwent elective coronary revascularisation, $n=569$ patients were treated with PCI $(38 \%$ bare metal stent (BMS) and 63\% DES) and n=446 with CABG. The analysis showed no significant differences between CABG and PCI (unadjusted HR for 1-year mortality 0.94 (0.71 to 1.24) for CABG, adjusted 1-year mortality HR 1.16 $(0.80$ to 1.67$)) .^{21}$

\section{Current recommendations}

Current recommendations are provided by cardiovascular, rather than renal guidelines. The European Renal Best Practice Guideline on kidney donor and recipient evaluation and perioperative care published in 2014 recommend "performing coronary angiography in renal transplant candidates with a positive test for cardiac ischemia. Further management should be according to the current cardiovascular guidelines'. ${ }^{22}$

The 2014 ESC/EACTS Guidelines on myocardial revascularisation have devoted a small section on patients with chronic renal disease. ${ }^{2}$ For patients with severe CKD and ESRD or in haemodialysis, the guidelines base their recommendation on a more recent study using USRDS registry data. ${ }^{3}$ The guidelines recommend that 'CABG should be considered over PCI in patients with multivessel CAD and symptoms/ischaemia whose surgical risk profile is acceptable and life expectancy is beyond 1 year' whereas 'PCI should be considered over CABG in patients with multivessel CAD and symptoms/ischaemia whose surgical risk profile is high or life expectancy is less than 1 year'. ${ }^{2}$ Both are Class IIb, level B recommendations. In figure 2 our results are integrated into the current guideline recommendations to show an amended proposed strategy for myocardial revascularisation for patients with ESRD on haemodialysis.

\section{ESRD populations}

Our analysis is the first large-scale report using data of patients who mainly have been treated according to current standard practice as patients underwent index revascularisation between 2010 and 2012. Demographics and healthcare seeking behaviour greatly differ between the German AOK and the US Medicare population. Medicare is the health insurance for all US citizens above 65 years and/or with disabilities and/or renal failure requiring chronic haemodialysis or transplantation. It covers hospital care, nursing facility care, nursing home care and hospice care, as well as ambulance services and limited outpatient care and prescription drugs. These latter services require extra monthly fees (http://www.medicare.gov). Around 16\% ( 50 Mio people) of the US population are covered by Medicare. ${ }^{23}$ Of these, 209000 people received Medicare coverage because of ESRD and another 175000 because of age and ESRD (2007). Medicare does not cover primary care or early stage disease management for comorbidities. ${ }^{24}$

AOK is Germany's largest public health insurance company. Health insurance is mandatory for all German citizens and covers all healthcare costs which are considered to be effective. People can choose private healthcare instead of public health insurance, if they have a yearly income above $€ 54900$. Compared with other public and with private insurances, AOK-insured persons

Patient with ESRD on dialysis and CAD requiring myocardial revascularization

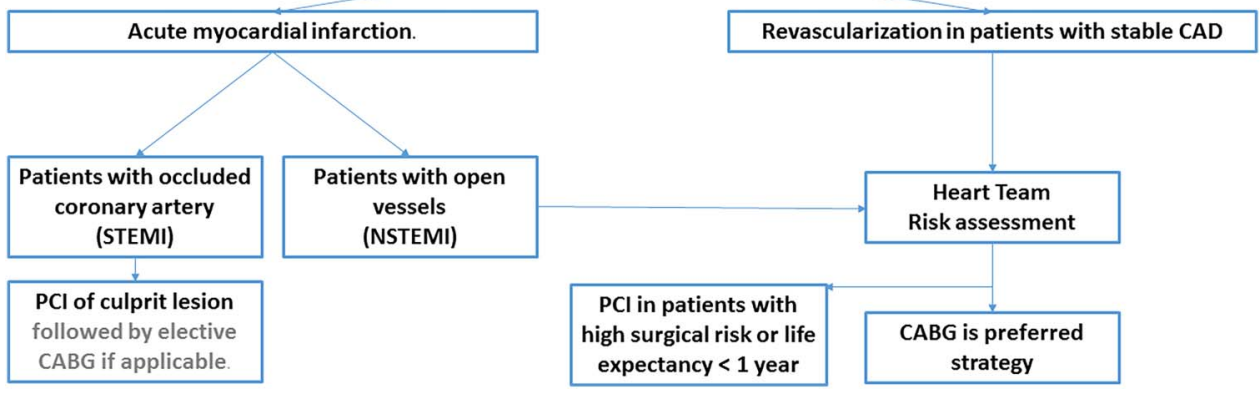

Figure 2 Proposed future revascularisation strategy in patients with ESRD based on our current results and previous guideline recommendations. AMI, acute myocardial infarction; CABG, coronary artery bypass graft; CAD, coronary artery disease; ESRD, end-stage renal disease; NSTEMI, non-ST-elevation myocardial infarction; STEMI, ST-elevation myocardial infarction. 
are more likely to be older, less likely to have a high school degree and more likely to perceive their health status as poorer than persons with private health insurance. ${ }^{25}$ Still, when comparing patient characteristics between the Medicare population reported by Chang et al and our cohort, the Medicare population is considerably younger (mean age CABG 63/PCI 65 years) than our patients (median age CABG 69/PCI 72 years), with a lower rate of AMI in the index hospitalisation (Medicare cohort: CABG 23.9\%/PCI 27.6\%, AOK: CABG 31.6/PCI 44.1\%) but with a higher prevalence of prior MI (CABG 17.5\%/PCI 20\% Medicare cohort, CABG 16.4/PCI 11.2\% AOK). Long-term mortality was significantly higher in the Medicare cohort, but follow-up time was longer (Medicare: 70.9\% CABG, 70.2\% PCI vs AOK: CABG 31.5\%, PCI 31.4\%).

\section{Acute MI}

Very few studies provide separate analyses for patients with acute coronary syndrome (ACS) and AMI even though optimal revascularisation strategies might be different in an elective versus an acute setting, given the high morbidity of this patient cohort.

Of the studies published in the past 10 years, only one trial by Shroff et $a l^{19}$ included and explicitly reported data on patients with AMI, the other studies either exclude patients with AMI, ${ }^{20} 2627$ only had elective patients in their cohort ${ }^{21}$ or did not report separate results for the subgroup of patients with AMI, ${ }^{3}$ 28-30 although Chang et al provide a sensitivity analysis, showing that the presence of AMI had no influence on the result of their study.

Shroff et al included 23033 patients with CKD stage 5 on renal replacement therapy for at least 90 days who were hospitalised for their first coronary revascularisation therapy, of these, $54.2 \%$ presented with ACS $(66 \%$ AMI and $34 \%$ unstable angina pectoris (UAP)). Overall survival was lower in the ACS group. Interestingly, patients with ACS greatly profited from CABG on the long-term whereas patients without ACS had a similar long-term outcome with CABG or PCI. In patients with ACS, the HR for predicting mortality in DES and BMS versus CABG was 1.08 (1.02 to 1.15) and 1.30 (1.21 to $1.38)$, respectively. In-hospital mortality was highest in patients with CABG (10.4\%) and lowest for DES (4.0\%). In non-ACS patients the HR for predicting mortality in DES and BMS versus CABG was 1.01 (0.95 to 1.07) and was only significant for BMS with 1.13 (1.05 to 1.22). ${ }^{19}$

In our cohort, patients with ESRD with AMI in the index hospital stay were at higher risk for short-term and long-term adverse outcomes, as compared to patients without AMI. Patients with AMI had longer hospital stays, higher mortality at 30 days and higher ORs at 1 year. In the subgroup of patients with AMI, the 30-day mortality did not differ significantly between the revascularisation strategies, but the OR for 1-year mortality and 1-year MACCE were 1.47 (1.08 to 1.99) and 1.40 (1.06 to $1.85)$ in PCI versus patients with CABG, respectively.
Importantly, patients with STEMI had a higher risk of death within 30 days $(\mathrm{OR}=2.16$ (1.56 to 2.98)) and therefore a potential negative influence on survival in the PCI group. The shorter door-to-balloon time in PCI might have a higher impact in patients with STEMI and PCI should probably be the preferred strategy in these patients.

\section{Limitations and external validity of health insurance data}

Registries usually have to rely on complete and accurate information without being able to validate the data. Since they are especially set up for future analyses, variables which are not routinely provided can be included in the report forms. Registries provide larger and more unselected data sets than clinical trials, although here source data verification guarantees valid information of the selected group of patients who met the inclusion criteria.

Using health insurance data for large-scale outcome analyses has become increasingly popular and compared to study and registry data they hold a number of advantages. The most obvious advantage is the large sample size and the completeness of available data, thus avoiding selection and recall bias. In particular data from clinical trials exclude a large number of patients, often older and multimorbid. Health insurance data also have the great advantage of providing intersectoral data from the inpatient and outpatient healthcare system. ${ }^{31}$

On the other hand, health insurance data are not originally generated to analyse processes and patient outcome but are primarily needed for budgeting and reimbursement. Thus, valuable information is lacking, including data on coronary anatomy, quality of life and lifestyle-related risk factors. Also, specific budget regulations can cause particular coding behaviour. Additionally, data from one health insurance do not necessarily represent the whole population of one country.

One limitation of secondary data analyses is caused by a lack of international coding of diseases (ICD-10) codes for the clinical classification of diseases. There is no specific ICD code for patients with ESRD by which these patients can be identified. We therefore chose to select patients with ESRD on the basis of the dialysis procedure rather than ICD codes.

Patient outcome after revascularisation is dependent on the chosen revascularisation strategy, and on the quality of postrevascularisation care. This important factor is not reflected in the current analysis.

\section{CONCLUSIONS}

Our data from a large German cohort of unselected patients with ESRD on haemodialysis undergoing either PCI or CABG due to stable and unstable CAD confirm older data from US registries. The 1-year long-term outcome was significantly better in patients with surgical revascularisation, with respect to mortality and MACCE. This was especially true for patients with AMI. 
The short-term outcome was significantly better in patients undergoing PCI. This was probably driven by patients with STEMI, suggesting that PCI might be the preferred revascularisation strategy for this patient group. Our data suggest that revascularisation strategies need to differentiate between patients with and without AMI. Patients with STEMI might profit from urgent PCI with subsequent elective CABG surgery.

Generally, long-term outcome is better for patients with ESRD undergoing CABG. In cases where the patient's characteristics and risk profile make it difficult to decide on a revascularisation strategy, CABG could be the preferred option.

\section{Author affiliations}

${ }^{1}$ Division of Emergency Medicine and Chest Pain Units, Department of Cardiology, Campus Virchow Klinikum and Campus Charité Mitte, CharitéUniversitätsmedizin Berlin, Berlin, Germany

${ }^{2}$ Department of Cardiology and Nephrology, Helios Klinikum, Berlin-Buch, Berlin, Germany

${ }^{3}$ Medical Service of the Health Funds (MDK) Baden-Württemberg, Lahr, Germany

${ }^{4}$ German Society of Cardiologists in Private Practise (BNK-Bundesverband niedergelassener Kardiologen), München, Germany

${ }^{5}$ Federal Association of the Local Health Care Funds (AOK), Berlin, Germany ${ }^{6}$ Faculty of Economics and Management, Division of Structural Development and Quality Management in Healthcare, Technische Universität Berlin, Berlin, Germany

${ }^{7}$ Research Institute of the Local Health Care Funds (WId0), Berlin, Germany

Contributors MM, HTB, PD, BL, JM, TM, CG and EJ held regular meetings to discuss the clinical need, research question, study design and data interpretation. MM, EJ and JS drafted the manuscript, including tables and figures and held regular meetings on content of the manuscript and data interpretation. EJ and CG performed the statistical analysis. All authors read and revised the manuscript.

Competing interests All authors have completed the Unified Competing Interests form at http://www.icmje.org/coi_disclosure.pdf (available on request from the corresponding author) and declare that MM has grants from Radiometer Medical ApS, Denmark, grants and non-financial support from ThermoFisher Scientific/Brahms AG, grants from Roche Diagnostics, grants from Novartis, grants from Cardiorentis, outside the submitted work; JS has grants from Radiometer Medical ApS, Denmark, grants from ThermoFisher Scientific/Brahms AG, grants from Roche Diagnostics, grants from Novartis, grants from Cardiorentis, outside the submitted work.

Provenance and peer review Not commissioned; externally peer reviewed.

Data sharing statement No additional data are available.

Open Access This is an Open Access article distributed in accordance with the Creative Commons Attribution Non Commercial (CC BY-NC 4.0) license, which permits others to distribute, remix, adapt, build upon this work noncommercially, and license their derivative works on different terms, provided the original work is properly cited and the use is non-commercial. See: http:// creativecommons.org/licenses/by-nc/4.0/

\section{REFERENCES}

1. Herzog CA, Ma JZ, Collins AJ. Long-term outcome of renal transplant recipients in the United States after coronary revascularization procedures. Circulation 2004;109:2866-71.

2. Windecker S, Kolh P, Alfonso F, et al. 2014 ESC/EACTS Guidelines on myocardial revascularization: the Task Force on Myocardial Revascularization of the European Society of Cardiology (ESC) and the European Association for Cardio-Thoracic Surgery (EACTS). Developed with the special contribution of the European Association of Percutaneous Cardiovascular Interventions (EAPCI). Eur Heart $J$ 2014;35:2541-619.

3. Chang TI, Shilane D, Kazi DS, et al. Multivessel coronary artery bypass grafting versus percutaneous coronary intervention in ESRD. J Am Soc Nephrol 2012;23:2042-9.

4. König J, Möckel M, Mueller E, et al. Risk-stratified cardiovascular screening including angiographic and procedural outcomes of percutaneous coronary interventions in renal transplant candidates. J Transplant 2014;2014:854397.

5. Kannan A, Poongkunran C, Medina R, et al. Coronary revascularization in chronic and end-stage renal disease: a systematic review and meta-analysis. Am J Ther 2016;23:e16-28.

6. Ren X, Liu W, Peng Y, et al. Percutaneous coronary intervention compared with coronary artery bypass graft in coronary artery disease patients with chronic kidney disease: a systematic review and meta-analysis. Ren Fail 2014;36:1177-86.

7. Chen YY, Wang JF, Zhang YJ, et al. Optimal strategy of coronary revascularization in chronic kidney disease patients: a meta-analysis. Eur J Intern Med 2013;24:354-61.

8. Deo SV, Shah IK, Dunlay SM, et al. Myocardial revascularisation in renal dysfunction: a systematic review and meta-analysis. Heart Lung Circ 2013;22:827-35.

9. Zheng $\mathrm{H}$, Xue $\mathrm{S}$, Lian $\mathrm{F}$, et al. Meta-analysis of clinical studies comparing coronary artery bypass grafting with percutaneous coronary intervention in patients with end-stage renal disease. Eur J Cardiothorac Surg 2013;43:459-67.

10. Health GFMo. Statutory Health Insurance Statistics KM1/13: Annual average 2012. Secondary Statutory Health Insurance Statistics KM1/ 13: Annual average 2012. 2013. http://www.bmg.bund.de/fileadmin/ dateien/Downloads/Statistiken/GKV/Mitglieder_Versicherte/KM1_ JD 2012.pdf

11. Information DIMDI DIfMDu. International Statistical Classification of Diseases and Related Health Problems 10th Revision. German Modification. Secondary International Statistical Classification of Diseases and Related Health Problems 10th Revision. German Modification. 2012. https://www.dimdi.de/static/de/klassi/icd-10-gm/ kodesuche/onlinefassungen/htmlgm2012/

12. Information DIfMDu. International Classification of Procedures in Medicine (ICPM). German Modification. Secondary International Classification of Procedures in Medicine (ICPM). German Modification. 2012. http://www.dimdi.de/static/de/klassi/ops/ kodesuche/onlinefassungen/opshtml2012/index.htm

13. Elixhauser A, Steiner C, Harris DR, et al. Comorbidity measures for use with administrative data. Med Care 1998;36:8-27.

14. Quan $\mathrm{H}$, Sundararajan V, Halfon $\mathrm{P}$, et al. Coding algorithms for defining comorbidities in ICD-9-CM and ICD-10 administrative data. Med Care 2005;43:1130-9.

15. Ivens $\mathrm{K}$, Gradaus $\mathrm{F}$, Heering $\mathrm{P}$, et al. Myocardial revascularization in patients with end-stage renal disease: comparison of percutaneous transluminal coronary angioplasty and coronary artery bypass grafting. Int Urol Nephrol 2001;32:717-23.

16. Herzog CA, Ma JZ, Collins AJ. Long-term outcome of dialysis patients in the United States with coronary revascularization procedures. Kidney Int 1999;56:324-32.

17. Herzog CA, Ma JZ, Collins AJ. Comparative survival of dialysis patients in the United States after coronary angioplasty, coronary artery stenting, and coronary artery bypass surgery and impact of diabetes. Circulation 2002;106:2207-11.

18. Krishnaswami A, Leong TK, Hlatky MA, et al. Temporal trends in mortality after coronary artery revascularization in patients with end-stage renal disease. Perm J 2014:18:11-16.

19. Shroff GR, Solid CA, Herzog CA. Impact of acute coronary syndromes on survival of dialysis patients following surgical or percutaneous coronary revascularization in the United States. Eur Heart J Acute Cardiovasc Care 2016;5:205-13.

20. Bangalore S, Guo Y, Samadashvili Z, et al. Revascularization in patients with multivessel coronary artery disease and chronic kidney disease: everolimus-eluting stents versus coronary artery bypass graft surgery. J Am Coll Cardiol 2015;66:1209-20.

21. Krishnaswami A, McCulloch CE, Tawadrous M, et al. Coronary artery bypass grafting and percutaneous coronary intervention in patients with end-stage renal disease. Eur J Cardiothorac Surg 2015;47:e193-8.

22. Abramowicz D, Cochat P, Claas FH, et al. European Renal Best Practice Guideline on kidney donor and recipient evaluation and perioperative care. Nephrol Dial Transplant 2015;30:1790-7.

23. Foundation THJKF. Medicare Beneficiaries as a Percent of Total Population. Secondary Medicare Beneficiaries as a Percent of Total Population 2012. http://kff.org/medicare/state-indicator/ medicare-beneficiaries-as-of-total-pop/ 
24. Knauf F, Aronson PS. ESRD as a window into America's cost crisis in health care. J Am Soc Nephrol 2009;20:2093-7.

25. Hoffmann F, Icks A. [Structural differences between health insurance funds and their impact on health services research: results from the Bertelsmann Health-Care Monitor]. Gesundheitswesen 2012;74:291-7.

26. Marui A, Kimura T, Nishiwaki N, et al. Percutaneous coronary intervention versus coronary artery bypass grafting in patients with end-stage renal disease requiring dialysis (5-year outcomes of the CREDO-Kyoto PCI/CABG Registry Cohort-2). Am J Cardiol 2014;114:555-61.

27. Terazawa S, Tajima K, Takami Y, et al. Early and late outcomes of coronary artery bypass surgery versus percutaneous coronary intervention with drug-eluting stents for dialysis patients. J Card Surg 2012;27:281-7.
28. Manabe S, Shimokawa T, Fukui T, et al. Coronary artery bypass surgery versus percutaneous coronary artery intervention in patients on chronic hemodialysis: does a drug-eluting stent have an impact on clinical outcome? J Card Surg 2009;24:234-9.

29. Sunagawa G, Komiya T, Tamura N, et al. Coronary artery bypass surgery is superior to percutaneous coronary intervention with drug-eluting stents for patients with chronic renal failure on hemodialysis. Ann Thorac Surg 2010;89:1896-900. discussion 900.

30. Yeates A, Hawley C, Mundy J, et al. Treatment outcomes for ischemic heart disease in dialysis-dependent patients. Asian Cardiovasc Thorac Ann 2012;20:281-91.

31. Ohlmeier C, Frick J, Prütz F, et al. [Use of routine data from statutory health insurances for federal health monitoring purposes]. Bundesgesundheitsblatt Gesundheitsforschung Gesundheitsschutz 2014; 57:464-72. 